\title{
Retenção e dessorção competitivas de ânions inorgânicos em gibbsita natural de solo
}

\author{
Adélia Aziz Alexandre Pozza ${ }^{(1)}$, Nilton Curi(1), Enio Tarso de Souza Costa(1), Luiz Roberto Guimarães Guilherme ${ }^{(1)}$, \\ João José Granate de Sá e Melo Marques(1) e Paulo Emílio Ferreira da Motta ${ }^{(2)}$
}

\begin{abstract}
(1)Universidade Federal de Lavras, Dep. de Ciência do Solo, Caixa Postal 3037, CEP 37200-000 Lavras, MG. E-mail: alana@ufla.br, niltcuri@ufla.br, eniotarso@yahoo.com.br, guilherm@ufla.br, jmarques@ufla.br (2)Embrapa Solos, Rua Jardim Botânico, no 1.024, Jardim Botânico, CEP 22460-000 Rio de Janeiro, RJ. E-mail: motta@cnps.embrapa.br
\end{abstract}

\begin{abstract}
Resumo - O objetivo deste trabalho foi quantificar a retenção e a dessorção competitivas dos ânions nitrato, sulfato, silicato e fosfato na fração argila gibbsítica de um Gleissolo Melânico. Amostras da fração argila foram agitadas em tubos de centrífuga com solução de $\mathrm{NaCl} 30 \mathrm{mmol}_{\mathrm{c}} \mathrm{L}^{-1}$ contendo estes ânions em quantidades equivalentes a 30\% das respectivas capacidades máximas de retenção exibidas pela argila. Para fins comparativos, as amostras foram agitadas com a mesma solução contendo $1 \mathrm{mmol}_{\mathrm{c}} \mathrm{L}^{-1}$ de cada um dos ânions citados. Os tubos foram centrifugados e determinaram-se as concentrações aniônicas nos sobrenadantes. A dessorção foi realizada agitando-se a fração argila remanescente nos tubos de centrífuga com a solução de $\mathrm{NaCl}$, quantificando-se os ânions liberados. Em outro ensaio, com o silício e o fósforo previamente adsorvidos à gibbsita, adicionou-se, na seqüência, o fósforo e o silício intercalados para avaliar a capacidade de dessorver o ânion previamente adsorvido. $\mathrm{O}$ fosfato foi preferencialmente adsorvido em relação aos demais ânions estudados e a aplicação prévia de silício reduziu a fixação de fosfato. Desse modo, a aplicação de silício previamente à de fósforo favorece a fitodisponibilidade deste em solos altamente intemperizados.
\end{abstract}

Termos para indexação: adsorção, competição, hidróxido de Al, solo oxídico.

\section{Competitive retention and desorption of inorganic anions on natural soil gibbsite}

\begin{abstract}
The objective of this work was to quantify the competitive retention and desorption of nitrate, sulfate, silicate and phosphate anions on gibbsitic clay fraction of a Melanic Gleisol. Samples of clay fraction were shaken in centrifuge tubes with $30 \mathrm{mmol}_{c} \mathrm{~L}^{-1} \mathrm{NaCl}$ solution containing these anions in quantities equivalent to $30 \%$ of the respective maximum adsorption capacity exhibited by clay. For comparative purposes, samples were also shaken with the same solution containing $1 \mathrm{mmol}_{c} \mathrm{~L}^{-1}$ of each mentioned anion. The tubes were centrifuged and the anionic concentrations in supernatants were determined. The dessorption was performed by shaking the residual clay fraction in centrifuge tubes with $\mathrm{NaCl}$ solution and quantifying the released anions. In another experiment, with the silicon phosphorus previously adsorbed to gibbsite, $\mathrm{P}$ and $\mathrm{Si}$ were added in the sequence, intercalated for evaluating the capacity of desorpting the previously adsorbed anion. The phosphate was preferentially adsorbed in relation to the other studied anions and the previous silicon application reduced the phosphate fixation. The silicon application previously to phosphate favours the bioavailability of $\mathrm{P}$ in highly weathered soils.
\end{abstract}

Index terms: retention, competition, $\mathrm{Al}$ hydroxide, oxidic soil.

\section{Introdução}

Reações de adsorção ocorrem principalmente na fração argila e na matéria orgânica do solo, e os óxidos (que incluem óxidos, oxidróxidos e hidróxidos) de alumínio, ferro e manganês, entre outros, são as superfícies inorgânicas reativas mais representativas em solos de carga variável (Sparks, 1995; Valladares et al., 2003). Óxidos de Al sintéticos apresentam elevada área superficial específica (100 a $220 \mathrm{~m}^{2} \mathrm{~g}^{-1}$ ), elevado ponto de carga zero (PCZ 9,5 a 10) e carga superficial variável. Esses minerais apresentam sítios superficiais para a adsorção química de cátions e ânions orgânicos e inorgânicos (Goldberg et al., 1996).

A adsorção pode ser conceituada como a acumulação de uma substância ou material na interface entre a superfície sólida e a solução. Três tipos de adsorção de ânions foram sugeridos por Hingston et al. (1974): 
(a) adsorção não específica - alguns ânions como $\mathrm{NO}_{3}{ }^{-}$ podem ser adsorvidos somente por superfícies carregadas positivamente, sendo fracamente retidos na camada difusa; (b) adsorção específica de ânions de ácidos completamente dissociados, tais como $\mathrm{SO}_{4}{ }^{2-}-$ estes ânions são adsorvidos quimicamente, envolvendo uma troca de ligantes com a $\mathrm{H}_{2} \mathrm{O}$ de superfície; (c) adsorção específica de ânions de ácidos incompletamente dissociados, tais como fosfato e silicato (ou ácido silícico) - a adsorção de tais ânions envolve troca com grupos $\mathrm{OH}^{-}$de superfície.

Posteriormente, outro esquema de grupamento de ânions foi proposto por Hsu (1989) com base em mecanismos de adsorção visando explicar as diferenças de mobilidade exibidas por íons negativamente carregados em solos: (a) ânions com fraca afinidade, tais como $\mathrm{NO}_{3}{ }^{-}$- estes ânions podem estar presentes somente na camada difusa exceto em sistemas completamente desidratados; (b) ânions com afinidade moderada, tais como $\mathrm{SO}_{4}{ }^{2-}$ - como descrito anteriormente; (c) ânions com forte afinidade, tais como fosfato - a afinidade deste íon por $\mathrm{Al}^{3+}$ é forte o suficiente para remover $\mathrm{OH}^{-}$da superfície ou para liberar $\mathrm{H}^{+}$de $\mathrm{H}_{3} \mathrm{PO}_{4}, \mathrm{H}_{2} \mathrm{PO}_{4}^{-}$ou $\mathrm{HPO}_{4}{ }^{2-}$; (d) ânions com afinidade muito forte, tais como $\mathrm{F}^{-}$- os ânions nesta categoria quebram o interior das ligações $\mathrm{Al}-\mathrm{OH}-\mathrm{Al}$, além de remover os grupos $\mathrm{OH}^{-}$de superfície nãocompartilhados. Recentemente, a distinção entre os diferentes tipos de adsorção tem sido feita considerandose a adsorção específica como a formação de complexos de esfera interna - sem a presença de $\mathrm{H}_{2} \mathrm{O}$ entre o ânion e a superfície adsorvente - e a adsorção não específica como sendo a formação de complexos de esfera externa com a presença de moléculas de $\mathrm{H}_{2} \mathrm{O}$ entre o ânion e a superfície adsorvente (Sparks, 1995).

O sulfato é sempre retido menos fortemente que o fosfato por $\mathrm{Al}(\mathrm{OH})_{3}$ numa ampla faixa de $\mathrm{pH}$. $\mathrm{O}$ sulfato adsorvido é completamente deslocado pelo fosfato, mas a recíproca não é verdadeira (Hsu, 1989). Isto ajuda a explicar a maior movimentação de sulfato no solo após a adubação fosfatada.

A adsorção de silício nas superfícies reativas dos minerais, precedente à aplicação de fosfato, parece promissora em aumentar a disponibilidade de fosfato em solos com elevada capacidade de retenção deste ânion, haja vista a molécula $\mathrm{H}_{4} \mathrm{SiO}_{4}$ ser considerada competidora do íon fosfato por sítios de adsorção do solo. Tal competição pode fazer com que o ácido silícico favoreça a dessorção de fosfato e vice-versa
(Leite, 1997; Carvalho et al., 2000; Camargo et al., 2005).

A adsorção de nitrato em solos de carga variável tende a aumentar em profundidade, e este fenômeno está associado ao incremento do número de cargas elétricas positivas nesta direção (Dynia, 2000; Dynia et al., 2006). Isto tende a dificultar a lixiviação desse oxiânion (Araújo et al., 2004), implicando diminuição da eutrofização de aqüíferos.

A frequiência de ocorrência de gibbsita $\left[\mathrm{Al}(\mathrm{OH})_{3}\right]$ é substancialmente maior em solos bastante evoluídos e com pH baixo, destacando-se no Brasil o bioma Cerrado, tipificado pelos solos gibbsíticos das chapadas (Marques et al., 2004). Conforme Huang et al. (2002), neste bioma há registros de solos contendo mais de $950 \mathrm{~g} \mathrm{~kg}^{-1} \mathrm{de}$ gibbsita na fração argila, o que representa um verdadeiro laboratório natural para estudos acerca deste óxido.

Não existem tratamentos de dissolução seletiva específicos para óxidos de $\mathrm{Al}$, ao contrário dos óxidos de $\mathrm{Fe}$, por isso são necessárias pesquisas sobre o comportamento da gibbsita natural em solos, especialmente no que se refere à retenção e à dessorção competitivas de oxiânions inorgânicos, com repercussões no manejo de solos altamente intemperizados.

O objetivo deste trabalho foi quantificar a retenção e a dessorção competitivas dos ânions nitrato, sulfato, silicato e fosfato na fração argila gibbsítica de um Gleissolo Melânico.

\section{Material e Métodos}

Utilizaram-se amostras da fração argila de um Gleissolo Melânico, textura argilosa, localizado no Planalto Central brasileiro, em Uberaba, MG, a uma altitude de $930 \mathrm{~m}, 19^{\circ} 30^{\prime} \mathrm{S}$ e $48^{\circ} 8^{\prime} \mathrm{O}$. Esse tipo de solo ocorre ao longo da linha de drenagem da chapada, cujos horizontes subsuperficiais têm a mineralogia da fração argila constituída quase que exclusivamente por gibbsita (>950 $\mathrm{g} \mathrm{kg}^{-1}$ ) (Huang et al., 2002). O horizonte selecionado foi classificado como $4 \mathrm{Cg} 2$, com profundidade de $65-90 \mathrm{~cm}$, de cor branca $(\mathrm{N} 8 /$, úmido), com mosqueados proeminentes vermelhoacinzentados (10R 5/3, úmido); textura franco-siltosa; estrutura moderada grande prismática; consistência firme, plástica e pegajosa, com raízes apenas no interior das fendas entre os prismas. $\mathrm{O} \mathrm{pH}$ em água das amostras deste horizonte é 5,8 e o PCZ, determinado por mobilidade eletroforética, do material gibbsítico é 6,4. 
Quanto à extração da fração argila, $50 \mathrm{~g}$ de terra fina secada ao ar (TFSA) foram colocados em béquer de $250 \mathrm{~mL}$, no qual adicionaram-se $50 \mathrm{~mL}$ de solução ( $25 \mathrm{~mL}$ de $\mathrm{NaOH} 0,1 \mathrm{~mol} \mathrm{~L}^{-1}$ e $25 \mathrm{~mL}$ de água destilada), seguindo-se o procedimento padrão para a obtenção da fração argila por sedimentação (Embrapa, 1997). Após a extração, a argila foi purificada por meio de diálise e liofilizada. O termo gibbsita será utilizado com o sentido de significar fração argila com mais de $950 \mathrm{~g} \mathrm{~kg}^{-1} \mathrm{de}$ gibbsita deste solo.

A fim de avaliar a capacidade competitiva entre os ânions fosfato, nitrato, sulfato e silicato pelos sítios de adsorção da gibbsita, $0,5 \mathrm{~g}$ da fração argila do material gibbsítico foi suspenso em $50 \mathrm{~mL}$ da solução de $\mathrm{NaCl} 30 \mathrm{mmol} \mathrm{L}^{-1}$, contendo $0,20 \mathrm{mmol} \mathrm{L}^{-1} \mathrm{de}$ fosfato, $0,52 \mathrm{mmol} \mathrm{L}^{-1}$ de silicato, $0,11 \mathrm{mmol} \mathrm{L}^{-1} \mathrm{de}$ sulfato e $0,014 \mathrm{mmol} \mathrm{L}^{-1}$ de nitrato. Com uma relação solo:solução igual a 1:100, as quantidades de ânions adicionadas equivaleram a 20, 52, 11 e 1,4 mmol kg-1, valores que corresponderam a $30 \%$ das respectivas capacidades máximas de adsorção (CMA) desses íons anteriormente determinadas no material. A fim de evitar a ocorrência de outros fenômenos, como o da precipitação em superfície, optou-se por se ocupar apenas 30\% das CMAs, evitando-se saturar o complexo sortivo do material gibbsítico. Para efeito comparativo, um experimento paralelo foi realizado, utilizando-se a solução de $\mathrm{NaCl} 30 \mathrm{mmol} \mathrm{L}^{-1}$, contendo $1 \mathrm{mmol} \mathrm{L}^{-1}$ de fosfato, silicato, e nitrato e $0,5 \mathrm{mmol} \mathrm{L}^{-1}$ de sulfato. Apesar de o ácido silícico $\left(\mathrm{H}_{4} \mathrm{SiO}_{4}\right)$ corresponder à única forma de $\mathrm{Si}$ presente na solução, procurou-se adicionar uma quantidade equivalente de carga $\left(1 \mathrm{mmol} \mathrm{L}^{-1}\right.$ igual a $\left.100 \mathrm{mmol}_{\mathrm{c}} \mathrm{kg}^{-1}\right)$ de cada um dos demais ânions de modo a serem anulados possíveis efeitos da concentração sobre a adsorção. Após a adição da solução, as amostras foram agitadas por 24 horas e em seguida centrifugadas por 30 minutos a $3.600 \mathrm{rpm}$ para a coleta do sobrenadante.

Ao material sólido remanescente nos tubos de centrífuga, foram adicionados $50 \mathrm{~mL}$ da solução de $\mathrm{NaCl}$ $30 \mathrm{mmol} \mathrm{L}^{-1}$ para promover a dessorção. Procurou-se manter a mesma relação solo:solução, sendo as amostras agitadas por mais 24 horas e em seguida centrifugadas para separação dos sobrenadantes.

Tanto nos estudos de adsorção quanto nos de dessorção, os sobrenadantes foram analisados por espectrofotometria de absorção molecular em equipamento Varian - Cary 1 com vistas às quantificações de nitrato (Embrapa, 1999), silício (Jones $\&$ Dreher, 1996) e fosfato (Murphy \& Riley, 1962). O íon sulfato foi quantificado por meio de turbidimetria do sulfato de bário (Embrapa, 1999).

$\mathrm{Na}$ avaliação da capacidade do ânion fosfato em deslocar o silício e do silício em deslocar o ânion fosfato, nos sítios de adsorção da gibbsita, $0,5 \mathrm{~g}$ do material gibbsítico foi suspenso em $50 \mathrm{~mL}$ da solução de $\mathrm{NaCl}$ $30 \mathrm{mmol} \mathrm{L}^{-1}$, contendo $0,20 \mathrm{e} 1 \mathrm{mmol} \mathrm{L}^{-1}$ de fosfato e 0,52 e $1 \mathrm{mmol} \mathrm{L}^{-1}$ de silício. Com a relação solo:solução igual a 1:100, essas quantidades adicionadas foram equivalentes a 20 e $100 \mathrm{mmol}_{\mathrm{c}} \mathrm{kg}^{-1}$ de fosfato e a $52 \mathrm{e}$ $100 \mathrm{mmol} \mathrm{kg}^{-1}$ de silício, respectivamente. Após a adição da solução de adsorção, as amostras foram agitadas por 24 horas e, em seguida, centrifugadas por 30 minutos a $3.600 \mathrm{rpm}$ para a coleta do sobrenadante.

Ao material residual da adsorção nos tubos de centrífuga, foram adicionados $50 \mathrm{~mL}$ da solução de $\mathrm{NaCl}$ $30 \mathrm{mmol} \mathrm{L}^{-1}$ contendo outro ânion com sua respectiva concentração, para avaliar a capacidade do ânion presente nesta solução de deslocar o outro previamente adsorvido. Procurou-se manter a mesma relação solo: solução, e as amostras foram agitadas por mais 24 horas e, em seguida, centrifugadas, usando o mesmo procedimento adotado na adsorção. A primeira concentração do ânion na solução se refere a $30 \%$ da CMA do mesmo, obtida em experimentos anteriores e, a segunda foi utilizada para efeito comparativo, procurando-se manter a mesma concentração e anulando-se os possíveis efeitos que esta poderia exercer na dessorção competitiva. As quantificações de fosfato e silício nos sobrenadantes foram efetuadas conforme mencionado.

Todas as avaliações deste trabalho foram realizadas em triplicata, mantendo-se o pH em torno de 5,5 $\pm 0,2$, ajustado por meio de adições de $\mathrm{NaOH}$ ou $\mathrm{HCl}$. Foi calculado o desvio-padrão da média para os valores das quantidades adicionadas, adsorvidas e dessorvidas.

\section{Resultados e Discussão}

Na adsorção competitiva, com a adição de $30 \%$ da CMA dos ânions, os valores obtidos obedeceram à sequiência crescente: nitrato<sulfato <<<silicato<fosfato. $\mathrm{Na}$ adição de $100 \mathrm{mmol}_{\mathrm{c}} \mathrm{kg}^{-1}$, observou-se pequena alteração nessa sequiência: a posição dos dois primeiros ânions inverteu-se e a seqüência crescente de adsorção passou a ser: sulfato $<$ nitrato $<<<$ silicato $<$ fosfato (Figura $1 \mathrm{~A}$ ). No caso 
da adição de $30 \%$ da CMA, como não houve equivalência das cargas, provavelmente a carga do sulfato (divalente) está mascarando a do nitrato (monovalente), o que pôde ser confirmado quando se fez a equivalência das cargas.

Ainda considerando-se a adição de $30 \%$ da CMA, o silicato foi $53,2 \%$ menos adsorvido do que o fosfato, enquanto o sulfato e o nitrato foram 94,4 e 97,0\% menos adsorvidos, respectivamente. Em ambas as quantidades adicionadas, o ânion mais retido foi o fosfato, indicando maior afinidade pela gibbsita em comparação com os demais ânions. A diferença positiva entre o valor de PCZ da gibbsita estudada $(6,4)$ e o de $\mathrm{pH}$, em que os experimentos foram realizados a $\mathrm{pH} 5,5 \pm 0,2$, resulta em balanço líquido de cargas positivas, o qual favorece atração entre a superfície do material gibbsítico e os ânions.

Na dessorção competitiva (Figura 1 B), observou-se inversão no comportamento do silicato com o fosfato nas doses adicionadas. Na dose $30 \%$ da CMA, a quantidade dessorvida de fosfato foi $69,1 \%$ menor do que a de silicato, embora em $\mathrm{pH}$ 5,5, o ácido silícico não esteja dissociado para formar silicato - menos que $0,01 \%$ - por isso, doravante, para efeito de simplificação, o termo silício será adotado para tratar do silício adsorvido ou dessorvido na forma de ácido silícico.

Para a adição de $100 \mathrm{mmol}_{\mathrm{c}} \mathrm{kg}^{-1}$, a quantidade dessorvida de silício foi $38,6 \%$ menor do que a de fosfato.
Em menores doses, o silício foi mais dessorvido do que o fosfato, e em maiores doses isto não ocorreu. Os valores das constantes de ionização parcial dos ácidos fosfórico e silícico fazem com que as espécies predominantes de fósforo e de silício, em soluções aquosas com pH 5,5, correspondam aos ânions $\mathrm{H}_{2} \mathrm{PO}_{4}^{-}$ e à forma neutra $\mathrm{H}_{4} \mathrm{SiO}_{4}{ }^{0}$. Desse modo, a carga negativa do íon fosfato tende a favorecer sua adsorção preferencial pela superfície positivamente carregada da gibbsita.

Na adição de $30 \%$ da CMA, a quantidade dessorvida de sulfato foi $87,9 \%$ e de nitrato foi $87,5 \%$ menor do que a de fosfato e, com a adição de $100 \mathrm{mmol}_{\mathrm{c}} \mathrm{kg}^{-1}$, a quantidade dessorvida de sulfato foi $96,7 \%$, e de nitrato 99,7\% menor do que a de silício. Em ambas as doses, as adsorções de nitrato e sulfato também foram baixas (Figura $1 \mathrm{~A}$ ), comparadas às de silício e fósforo, confirmando os dados de Hingston et al. (1974) e Hsu (1989).

Os valores obtidos na adsorção de nitrato são consonantes com os encontrados na literatura. Oliveira et al. (2000) observaram aumento de 0 a $3,5 \mathrm{mmol} \mathrm{kg}^{-1}$ na adsorção de nitrato em Latossolo Vermelho-Escuro com a profundidade, e Dynia (2000) observou aumento de 0 a 6,0 mmol kg-1 em três tipos de solo. Este último autor associou a adsorção de nitrato ao fato de todos os solos terem aumentado o número de cargas elétricas positivas em profundidade. Esse fato torna-se muito
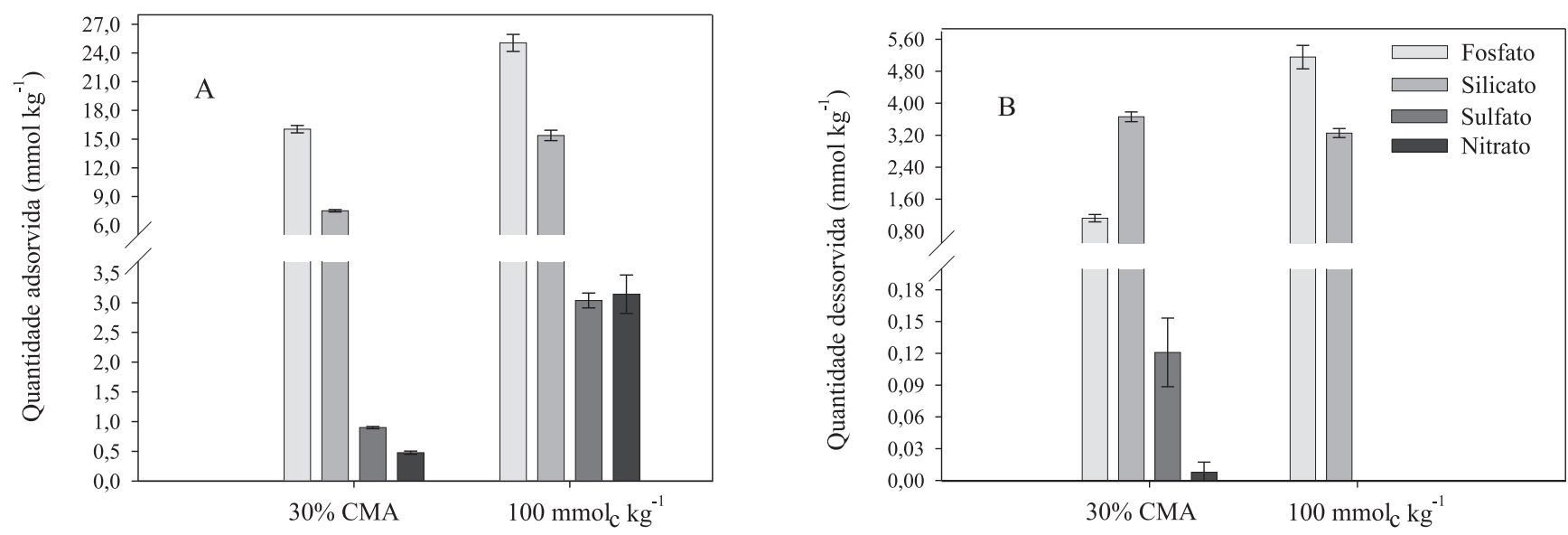

Quantidade adicionada na adsorção

Figura 1. A: Adsorção competitiva de ânions na gibbsita natural de solo com a adição simultânea de $30 \%$ da capacidade máxima de adsorção (CMA) (20,0 mmol $\mathrm{kg}^{-1}$ de fosfato, 52,0 mmol $\mathrm{mg}^{-1}$ de silicato, 11,0 mmol $\mathrm{mg}^{-1} \mathrm{de} \mathrm{sulfato} \mathrm{e} 1,4 \mathrm{mmol}_{\mathrm{c}} \mathrm{kg}^{-1} \mathrm{de}$ nitrato) e também de $100 \mathrm{mmol}_{\mathrm{c}} \mathrm{kg}^{-1}$ de cada. B: Dessorção dos mesmos ânions nas mesmas concentrações. Relação

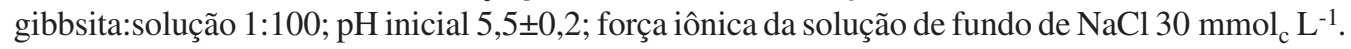


importante do ponto de vista de contaminação de lençóis freáticos por nitrato, já que o aumento da adsorção em maiores profundidades implica menor lixiviação para os lençóis, reduzindo a possibilidade de eutrofização de aqüíferos.

No experimento de competição entre fósforo e silício, para a quantidade inicial adicionada de $30 \%$ da CMA desses ânions, a quantidade adsorvida de fosfato, antes da adição de ácido silícico, foi 13,1 mmol kg-1 e, após a adição deste ao resíduo nos tubos de centrífuga, a adsorção do fosfato foi reduzida para $12,2 \mathrm{mmol} \mathrm{kg}{ }^{-1}$ (Figura $2 \mathrm{~A}$ ). Essa quantidade de fosfato continuou adsorvida à gibbsita mesmo após a adição de silício, isto é, do fosfato inicialmente adsorvido à gibbsita, apenas $6,8 \%$ foi deslocado para a solução de equilíbrio, devido à adição de silício após o fosfato. Quando a amostra de gibbsita foi saturada anteriormente com silício e em seguida adicionou-se o fosfato (Figura 2 B), a adsorção do fosfato aumentou $\left(15,9 \mathrm{mmol} \mathrm{kg}^{-1}\right)$, sendo maior do que a do fosfato quando adicionado previamente (Figura $2 \mathrm{~A}$ ). A quantidade adicionada de fosfato $\left(19,4 \mathrm{mmol} \mathrm{kg}^{-1}\right)$ foi aproximadamente 2,6 vezes menor do que a de silício $\left(50,1 \mathrm{mmol} \mathrm{kg}^{-1}\right)$, em função da menor CMA do fosfato $\left(65,9 \mathrm{mmol} \mathrm{kg}^{-1}\right)$ à gibbsita, comparada ao silício $\left(172,4 \mathrm{mmol} \mathrm{kg}^{-1}\right)$, por isso, no cálculo de $30 \%$ dessa capacidade, utilizou-se um valor menor para o fosfato $(20,0 \mathrm{mmol} \mathrm{kg}-1)$ em relação ao silício (52,0 mmol kg-1) (Figura 2).

$\mathrm{Na}$ maioria dos solos tropicais, o suprimento natural de fósforo é insatisfatório ao adequado crescimento de plantas. Apesar de o teor total de fósforo nestes solos ser significativo, uma baixíssima porcentagem desse total está presente na solução do solo. A concentração de equilíbrio para o máximo crescimento da maioria das plantas em solos tropicais tende a ser naturalmente mais baixa, quando comparada aos solos de clima temperado.

Com o silício aplicado previamente (Figura 2 B), sua adsorção foi de $10,7 \mathrm{mmol} \mathrm{\textrm {kg } ^ { - 1 }}$, embora tenham sido adicionados 50,1 mmol kg-1. Após a aplicação de fosfato, a quantidade adsorvida de silício foi reduzida para $5,4 \mathrm{mmol} \mathrm{kg}^{-1}$, isto é, a adição de fosfato após a aplicação de silício diminuiu a adsorção deste à gibbsita em 50,8\%, promovendo a dessorção de 5,2 $\mathrm{mmol} \mathrm{kg}^{-1}$ de silício para a solução de equilíbrio. Quando a amostra foi saturada previamente com fosfato (Figura $2 \mathrm{~A}$ ), a adsorção de silício foi reduzida, passando para $4,9 \mathrm{mmol} \mathrm{kg}{ }^{-1}$ ou $53,8 \%$ menos do que o silício adsorvido, quando adicionado inicialmente.
$\mathrm{Na}$ adição inicial de $100 \mathrm{mmol} \mathrm{kg}{ }^{-1}$ de fosfato e de silício (Figura 3), observou-se redução na porcentagem adsorvida dos ânions, quando comparada à porcentagem adsorvida nas menores doses (Figura 2). A porcentagem adsorvida de fosfato em relação à quantidade adicionada foi menor com a adição inicial de $100 \mathrm{mmol} \mathrm{kg}^{-1}(17 \%)$ (Figura $3 \mathrm{~A}$ ) comparada à adição inicial de $30 \%$ da CMA dos ânions (67,7\%) (Figura 2 A).

A quantidade adsorvida de fosfato, quando aplicado inicialmente, foi de $16,7 \mathrm{mmol} \mathrm{kg}^{-1}$ (Figura 3 A). Após a adição de silício ao resíduo nos tubos de centrífuga, a quantidade adsorvida de fosfato foi reduzida para $9,9 \mathrm{mmol} \mathrm{kg}$. . Mohapatra et al. (2005), Xu et al. (2006), Elzinga \& Sparks (2007) e Xiaofang et al. (2007), entre outros, realçaram a elevada capacidade de adsorção de fosfato em óxidos de $\mathrm{Al}$ e de Fe.

Quando a amostra de gibbsita foi saturada previamente com silício (Figura 3 B) e, em seguida, adicionou-se o fosfato, a adsorção de fosfato foi menor $(6,3 \mathrm{mmol} \mathrm{kg}-1)$ do que quando se adicionou o fosfato isoladamente $\left(16,8 \mathrm{mmol} \mathrm{kg}^{-1}\right)$ (Figura $3 \mathrm{~A}$ ).

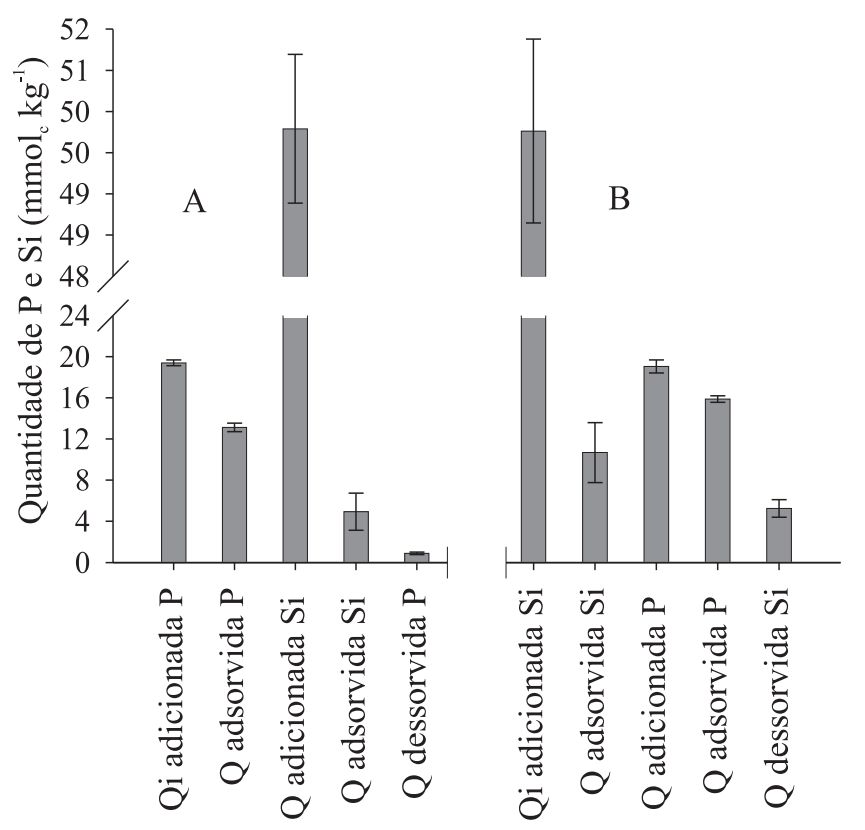

Figura 2. Quantidade adsorvida/dessorvida de silício e fosfato na gibbsita natural de solo, previamente saturada com fosfato (A) e silício (B), respectivamente. Quantidades adicionadas de fosfato e de silício correspondem a $30 \%$ da CMA. Qi adicionada: quantidade inicial adicionada para promover a adsorção; Q adicionada: quantidade adicionada para promover a adsorção do outro ânion e a dessorção do ânion previamente adsorvido. Relação gibbsita:solução 1:100;

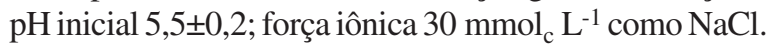

Pesq. agropec. bras., Brasília, v.42, n.11, p.1627-1633, nov. 2007 
A ordem de aplicação dos ânions influenciou o porcentual de fosfato adsorvido, isto é, a quantidade adsorvida de fosfato quando o silício foi aplicado após o tratamento inicial com fosfato foi $9,9 \mathrm{mmol} \mathrm{kg}^{-1}$ (Figura $3 \mathrm{~A}$ ), enquanto a quantidade adsorvida de fosfato, quando a amostra foi tratada inicialmente com silício, foi $6,3 \mathrm{mmol} \mathrm{kg}^{-1}$ (Figura $3 \mathrm{~B}$ ). Dessa forma, observouse a liberação de $40,9 \%$ do fosfato para a solução pela inversão da ordem de aplicação do silício.

Quando se adicionou o silício depois do tratamento prévio com fosfato (Figura $3 \mathrm{~A}$ ), observou-se a adsorção de 3,4 mmol kg-1 de silício, correspondendo a 34,9\% da adsorção, no caso desse ânion adicionado inicialmente $\left(9,7 \mathrm{mmol} \mathrm{kg}{ }^{-1}\right)$. O fosfato adicionado após o silício (Figura $2 \mathrm{~B}$ ) promoveu a dessorção de $2 \mathrm{mmol} \mathrm{kg}^{-1}$ do silício para a solução de equilíbrio, permanecendo retido na gibbsita 9 mmol kg-1 de silício.

A importância da ordem de aplicação do silício e do fosfato ao solo também foi constatada por Novelino (1999), o qual estudou a absorção de fósforo pelo sorgo

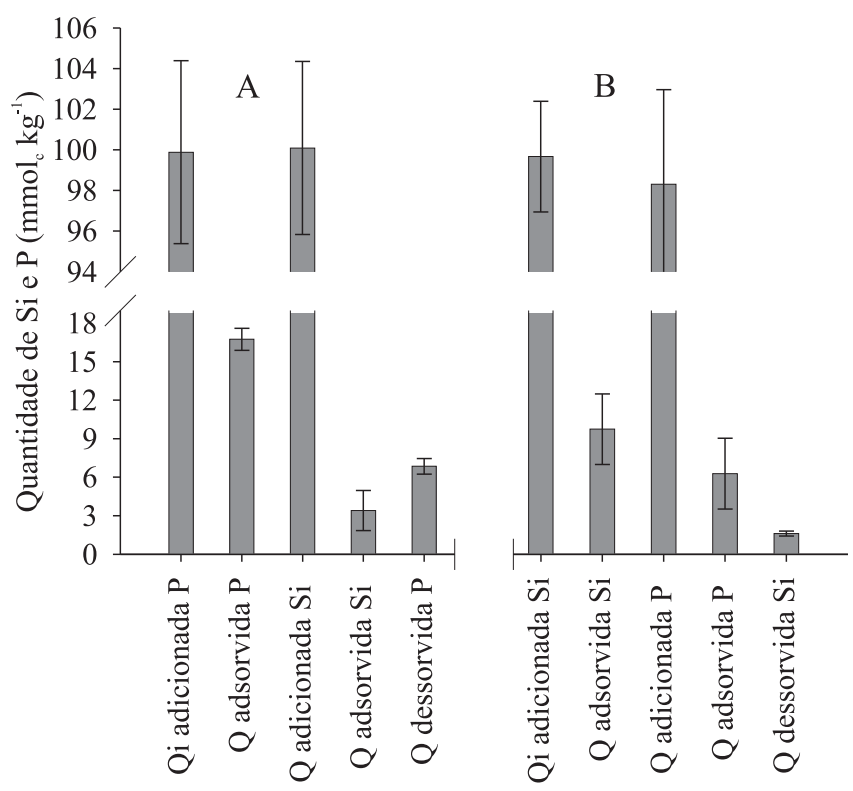

Figura 3. Quantidade adsorvida/dessorvida de silício e fosfato na gibbsita natural de solo, previamente saturada com fosfato (A) e silício (B), respectivamente. Quantidades de fosfato e de silício com adição de $100 \mathrm{mmol}_{\mathrm{c}} \mathrm{kg}^{-1}$ de cada. Qi adicionada: quantidade inicial adicionada para promover a adsorção; Q adicionada: quantidade adicionada para promover a adsorção do outro ânion e a dessorção do ânion previamente adsorvido. Relação gibbsita:solução 1:100; pH inicial 5,5 $\pm 0,2$; força iônica $30 \mathrm{mmol}_{\mathrm{c}} \mathrm{L}^{-1}$ como $\mathrm{NaCl}$. em um Latossolo Vermelho distroférrico, tratado com silício e fosfato, em casa de vegetação, e concluiu que a aplicação do silício previamente ao fosfato influenciou positivamente a absorção de fósforo pelo sorgo.

A adsorção de silício pelas superfícies dos minerais de argila do solo, precedente à aplicação de fosfato, tende a aumentar a disponibilidade de fosfato em solos oxídicos. Após sofrer desprotonação, o $\mathrm{H}_{4} \mathrm{SiO}_{4}$ residual transforma-se em $\mathrm{H}_{3} \mathrm{SiO}_{4}{ }^{-} \mathrm{e}$ adsorve-se à gibbsita, impedindo ou dificultando a adsorção de fosfato e tornando-o mais disponível em solução. Segundo Carvalho et al. (2001), esta é a principal forma de competição entre silício e fósforo, assumida por pesquisadores do tema nos últimos 20 anos. A ocorrência de competição entre o silício e o fósforo pelos mesmos sítios de adsorção do solo também foi sugerida por outros autores (Leite, 1997; Silva et al., 2003; Carneiro et al., 2006). Neste trabalho, no início, provavelmente, ocorreu aumento na concentração de ácido monossilícico na solução do solo, seguido pela adsorção à gibbsita. Em seguida, houve troca do fósforo pelo silício. Essas reações possivelmente foram seguidas pela dessorção do ânion fosfato, tornando-o mais disponível em solução e, assim, um novo equilíbrio dinâmico entre o silício e o fosfato foi estabelecido.

A velocidade das reações de adsorção do silício é alta na presença de minerais com superfícies altamente adsorvedoras, como no caso de solos tipicamente oxídicos, e, por isso, grande quantidade de silício pode ser adsorvida durante o ciclo de uma cultura. Dessa forma, a aplicação de silício deverá minimizar a aplicação de adubações fosfatadas pesadas, visto que o fosfato é transformado com o tempo em compostos mais estáveis, diminuindo sua disponibilidade para as plantas (Carvalho et al., 2001; Silva et al., 2003).

Sob condições de casa de vegetação, a adição de silicato ao solo aumentou a disponibilidade do fósforo para a cana-de-açúcar. Em teores semelhantes de fósforo, plantas tratadas com silicato desenvolveram-se melhor, indicando que o silício, possivelmente, favoreceu o aproveitamento do fósforo pelas plantas em decorrência do aumento da disponibilidade deste nutriente no solo (Ayres, 1966).

Os resultados obtidos neste trabalho podem ser extrapolados, por exemplo, para os solos gibbsíticos das chapadas do Bioma Cerrado, atualmente tão intensivamente cultivados, e contribuem também para incrementar o escasso banco de dados relativo aos óxidos de Al de ocorrência natural em solos brasileiros e no exterior. 


\section{Conclusões}

1. Na adsorção competitiva de ânions na superfície da gibbsita natural de solo destaca-se a ordem crescente: nitrato $<$ sulfato $<<<$ silicato $<$ fosfato.

2. O fosfato tem capacidade de deslocar o silício adsorvido à superfície da gibbsita e vice-versa.

3. A prévia aplicação de silício, seguida da aplicação de mesma quantidade molar de fosfato, reduz $40,9 \%$ da adsorção de fosfato à gibbsita, indicando a importância da sequiência de aplicação destes elementos no manejo da fertilidade de solos tropicais altamente intemperizados.

\section{Referências}

ARAÚJO, A.R.; CARVALHO, J.L.N.; GUILHERME, L.R.G.; CURI, N.; MARQUES, J.J. Movimentação de nitrato e amônio em colunas de solo. Ciência e Agrotecnologia, v.28, p.541-545, 2004.

AYRES,A.S. Calcium silicate slag as a growth stimulant for sugarcane on low-silicon soils. Soil Science, v.101, p.216-227, 1966.

CAMARGO, M.S.; KORNDÖRFER, G.H.; CORRÊA, G.F.; PEREIRA, H.S.; BARBOSA, D.S.; RESENDE, R.H. Extratores de silício solúvel em solos: influência do calcário e fósforo. Bioscience Journal, v.21, p.9-19, 2005.

CARNEIRO, C.E.A.; FIORETTO, R.A.; FONSECA, I.C.B.; CARNEIRO, G.E.S. Calcário, potássio, fosfato e silício na produtividade do solo. Acta Scientiarum, v.28, p.465-470, 2006.

CARVALHO, R.; FURTINI NETO, A.E.; CURI, N.; FERNANDES, L.A.; OLIVEIRA JUNIOR, A.C. Dessorção de fósforo por silício em solos cultivados com eucalipto. Revista Brasileira de Ciência do Solo, v.24, p.69-74, 2000 .

CARVALHO, R.; FURTINI NETO, A.E.; SANTOS, C.D.; FERNANDES, L.A.; CURI, N.; RODRIGUES, D.C. Interações silíciofósforo em solos cultivados com eucalipto em casa de vegetação. Pesquisa Agropecuária Brasileira, v.36, p.557-565, 2001.

DYNIA, J.F. Nitrate retention and leaching in variable charge soils of a watershed in São Paulo State, Brazil. Communications in Soil Science and Plant Analysis, v.31, p.777-791, 2000.

DYNIA, J.F.; SOUZA, M.D.; BOEIRA, R.C. Lixiviação de nitrato em Latossolo cultivado com milho após aplicações sucessivas de lodo de esgoto. Pesquisa Agropecuária Brasileira, v.41, p.855-862, 2006.

ELZINGA, E.J.; SPARKS, D.L. Phosphate adsorption onto hematite: an in situ ATR-FTIR investigation of the effects of $\mathrm{pH}$ and loading level on the mode of phosphate surface complexation. Journal of Colloid and Interface Science, v.308, p.53-70, 2007.

EMBRAPA. Manual de análises químicas de solos, plantas e fertilizantes. Brasília: Embrapa-SCT, 1999. 390p.

EMBRAPA. Manual de métodos de análise de solo. 2.ed.rev.atual. Rio de Janeiro: Embrapa-CNPS, 1997. 212p. (Embrapa-CNPS. Documentos, 1).

GOLDBERG, S.; DAVIS, J.A.; HEM, J.D. The surface chemistry of aluminum oxides and hydroxides. In: SPOSITO, G. (Ed.). The environmental chemistry of aluminum. Boca Raton: CRC Press, Lewis Publ., 1996. p.271-331.
HINGSTON, F.J.; POSNER, A.M.; QUIRK, J.P. Anion adsorption by goethite and gibbsite. II. Desorption of anions by hydrous oxide surfaces. Journal of Soil Science, v.25, p.16-26, 1974.

HSU, P.H. Aluminum hydroxides and oxyhydroxides. In: DIXON, J.B.; WEED, S.B. (Ed.). Minerals in soil environments. Madison: Soil Science Society of America, 1989. p.331-378.

HUANG, P. M.; WANG, M.K.; KÄMPF, N.; SCHULZE, D.G. Aluminum hydroxides. In: DIXON, J.B.; SCHULZE, D.G. Soil Mineralogy with Environmental Applications. Madison: Soil Science Society of America, 2002. p.261-289.

JONES, R.L.; DREHER, G.B. Silicon. In: SPARKS, D.L.; PAGE, A.L.; HELMKE, P.A.; LOEPPERT, R.H.; SOLTANPOUR, P.N.; TABATABAI, M.A.; JOHNSTON, C.T.; SUMMER, M.E. (Ed.). Methods of soil analysis: part 3: chemical methods. Madison: SSSAASA, 1996. p.627-638.

LEITE, P.C. Interação silício-fósforo em Latossolo Roxo cultivado com sorgo em casa de vegetação. 1997. 87p. Tese (Doutorado) Universidade Federal de Viçosa, Viçosa.

MARQUES, J.J.G.; SCHULZE, D.G.; CURI, N.; MERTZMAN, S.A. Major element geochemistry and geomorphic relationships in Brazilian Cerrado soils. Geoderma, v.119, p.179-195, 2004.

MOHAPATRA, D.; SINGH, P.; ZHANG, W.; PULLAMMANAPPALLIL, P. The effect of citrate, oxalate, acetate, silicate and phosphate on stability of synthetic arsenic-loaded ferrihydrite and Al-ferrihydrite. Journal of Hazardous Materials, v.124, p.95100, 2005.

MURPHY, J.; RILEY, D.J.P. A modified single solution method for the determination of phosphate in natural waters. Analytical Chemistry Acta, v.27, p.31-36, 1962.

NOVELINO, J.O. Disponibilidade de fósforo e sua cinética, em solos sob cerrado fertilizados com fósforo, avaliada por diferentes métodos de extração. 1999. 70p. Tese (Doutorado) - Universidade Federal de Viçosa, Viçosa, 1999.

OLIVEIRA, J.R.A.; VILELA, L.; AYARZA, M.A. Adsorção de nitrato em solos de cerrado do Distrito Federal. Pesquisa Agropecuária Brasileira, v.35, p.1199-1205, 2000.

SILVA, M.A.; NÓBREGA, J.C.A.; CURI, N.; SIQUEIRA, J.O.; MARQUES, J.J.G.S.M.; MOTTA, P.E.F. Frações de fósforo em latossolos. Pesquisa Agropecuária Brasileira, v.38, p.1197-1207, 2003. SPARKS, D.L. Environmental soil chemistry. San Diego: Academic Press, 1995. 276p.

VALLADARES, G.S.; PEREIRA, M.G.; ANJOS, L.H.C. Adsorção de fósforo em solos de argila de atividade baixa. Bragantia, v.62, p.111118, 2003.

XIAOFANG, Y.; DONGSHENG, W.; ZHONGXI, S.; HONGXIAO, T. Adsorption of phosphate at the aluminum (hydr)oxides-water interface: role of the surface acid-base properties. Colloids and Surfaces A. Physicochemistry Engineering Aspects, v.297, p.84-90, 2007.

XU, N.; CHRISTODOULATOS, C.; BRAIDA, W. Modeling the competitive effect of phosphate, sulfate, silicate, and tungstate anions on the adsorption of molybdate onto goethite. Chemosphere, v.64, p.1325-1333, 2006.

Recebido em 3 de maio de 2007 e aprovado em 29 de outubro de 2007 